\title{
Professora Emérita Eunice Maria Lima Soriano de Alencar
}

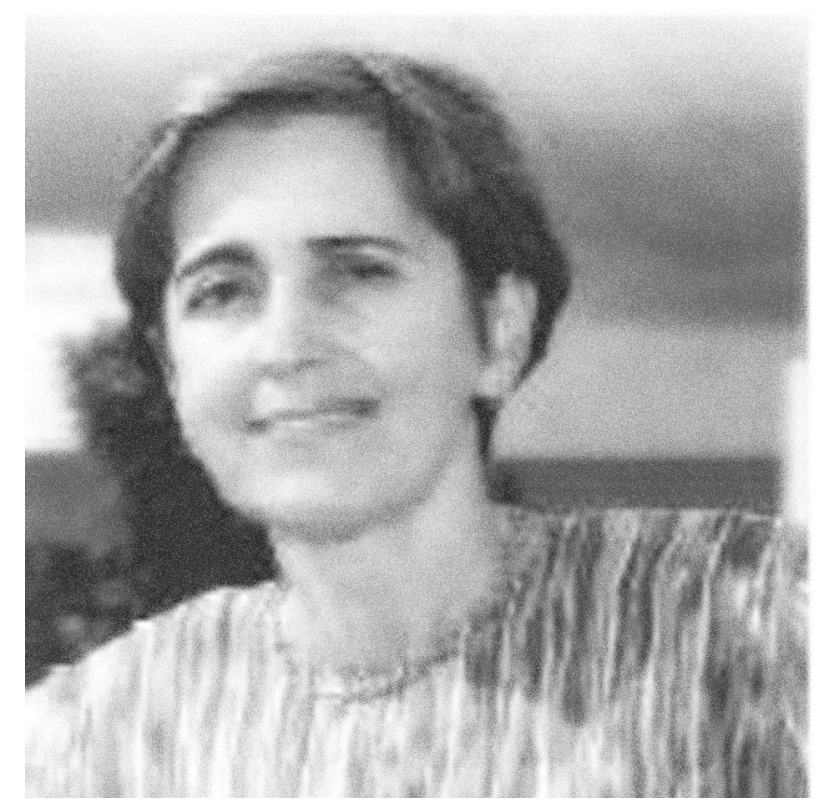

Figura 1. Professora Emérita Eunice Soriano de Alencar. Fonte: http://pepsic.bvs-psi.org.br/img/revistas/pee/v6n1/1a12f1.jpg

\section{Exposição de Motivos ${ }^{1}$}

A professora Eunice Maria Lima Soriano de Alencar nasceu aos 15 dias do mês de janeiro de 1945 em Teófilo Otoni, Minas Gerais. Em 1967, graduou-se em Psicologia pela Universidade Federal de Minas Gerais. Após concluir seu curso de graduação, permaneceu na instituição atuando como instrutora de ensino da disciplina Psicologia Médica durante sete semestres. Em 1970, concluiu seu mestrado na Purdue University, nos Estados Unidos da América com a dissertação "Theoretical contributions to the study of creativity". Dando continuidade à sua formação, cursou seu doutorado, na mesma instituição, no período de 1971 a 1974, tendo defendido a tese intitulada " $A$ study of creativity training among Brazilian elementary school". Em ambos os cursos, foi bolsista da United States Agency for International Development. No ano de 1985, a professora Eunice Alencar realizou seu pós-doutorado na Purdue University, sendo contemplada com bolsa da Fullbright.

A solicitação de outorga do título de professor emérito à professora Eunice Maria Lima Soriano de Alencar justifica-se por sua expressiva contribuição a) ao Instituto de Psicologia da Universidade de Brasília, nos níveis de ensino, pesquisa e extensão, pelo período de 25 anos em que a professora integrou o quadro docente permanente desta universidade; b) à área

1 Texto produzido pela Profa. Denise Fleith do Departamento de Psicologia Escolar e do Desenvolvimento da UnB como parte do processo de proposta de outorga de título de Professor Emérito à Eunice Maria Lima Soriano de Alencar. A editora agradece ao Departamento pela cessão deste texto para publicação. de Psicologia no País e c) a políticas públicas educacionais e tecnológicas. A seguir, tais contribuições serão detalhadas.

\section{Contribuição ao Instituto de Psicologia da Universidade de Brasília}

Dois anos antes de concluir seu doutoramento, a professora Eunice passou a integrar o quadro docente da Universidade de Brasília, com dedicação exclusiva. Em 1997 se aposentou no cargo de Professora Titular, após 25 anos de serviços prestados à instituição. Neste período, ministrou e criou diversas disciplinas na graduação e pós-graduação. Por duas vezes ocupou o cargo de chefe do Departamento de Psicologia Escolar e do Desenvolvimento do Instituto de Psicologia da Universidade de Brasília. Na área de extensão, coordenou inúmeros cursos, oficinas e palestras na área de criatividade e desenvolvimento de talentos. Participou, ainda, de várias bancas de defesa de dissertação de mestrado e tese de doutorado e orientou dissertações de mestrado.

É importante ressaltar, entretanto, que a contribuição da professora Eunice Alencar ao Instituto de Psicologia foi além das atividades rotineiras de um docente de instituição universitária. Há de se destacar que ela, por iniciativa e esforço próprios, foi responsável:

a) Pela criação, em 1985, da revista Psicologia: Teoria e Pesquisa, no então Departamento de Psicologia da Universidade de Brasília, considerada, até hoje, uma das mais concei- 
tuadas revistas da área no País. Foi, ainda, a primeira editora da revista, exercendo a função no período de 1985 a 1986.

b) Pela redação e encaminhamento, na segunda metade da década de 1980, da proposta de implantação do Programa Especial de Treinamento (PET) da Psicologia na UnB à CAPES, órgão do Ministério da Educação responsável pelo programa na ocasião. Foi a primeira tutora do Programa Especial de Treinamento (PET) da Psicologia, coordenando-o no período de 1987 a 1990 .

c) Pela implementação e desenvolvimento das linhas de pesquisa "Criatividade nos contextos educacional e organizacional" e "Processos de identificação e atendimento ao superdotado". Neste sentido, foi pioneira, na década de 1970, na implantação dessas áreas de estudo no País, contribuindo para que o Instituto de Psicologia se tornasse, como poucos no Brasil, um centro de excelência de investigação dos fenômenos da criatividade e superdotação. Atualmente, o Programa de Pós-Graduação do Instituto de Psicologia é um dos raros que conduzem pesquisas e oferecem cursos de mestrado e doutorado nas áreas mencionadas.

A análise do curriculum vitae da professora Eunice Alencar indica que, mesmo após ter se aposentado da Universidade de Brasília, passando a integrar o Programa de Mestrado em Educação da Universidade Católica de Brasília, ela mantém laços com o Instituto de Psicologia. Ela tem participado de bancas de defesas de trabalhos de mestrado e doutorado, exames de qualificação e desenvolvido projetos integrados de pesquisa na área de criatividade com docentes do Instituto, em especial com recém-doutores.

É importante, portanto, reconhecer o quanto a professora Eunice Alencar ajudou a tornar o Instituto de Psicologia da UnB expressivo no Brasil. Na análise a ser realizada a seguir também fica claro como a sua produção em periódicos estrangeiros contribuiu para projetar o Instituto em outros países.

\section{Contribuição à Área de Psicologia no País}

A professora Eunice Alencar tem se destacado por sua contribuição ao avanço da Psicologia no Brasil, em especial, das áreas de criatividade e superdotação. A análise da sua produção acadêmica, mencionada até março de $2003^{2}$, destaca a publicação de a) 110 artigos, sendo 80 em periódicos nacionais e 30 em periódicos internacionais de excelência, b) 23 trabalhos completos em anais de congressos, c) 12 livros, d) 21 capítulos de livros, e) 10 artigos em jornais de notícias e f) 5 artigos em revistas de divulgação. Seu curriculum vitae indica, ainda, a organização de três livros e apresentação de 107 trabalhos em congressos no Brasil e no exterior. Dentre os seus livros publicados, destacam-se: Psicologia da Criatividade, Psicologia e Educação do Superdotado, Como Desenvolver o Potencial Criador e Psicologia - Introdução aos Princípios Básicos do Comportamento, já em sua $13^{\mathrm{a}}$ edição.

Desde a década de 1980, a professora Eunice vem atuando como conselheira editorial e consultora ad hoc de revistas na área de Psicologia e Educação, tais como Psicologia: Ciência e Profissão (do Conselho Federal de Psicologia), Revista Brasileira de Estudos Pedagógicos, Psicologia: Reflexão e Crítica

2 A produção acadêmica do período mencionado corresponde ao momento em que este texto foi produzido. (da Universidade Federal do Rio Grande do Sul), Psicologia: Teoria e Pesquisa (da Universidade de Brasília), Humanidades (Universidade de Brasília), Cadernos de Pesquisa do NEP, Psicologia Escolar e Educacional, Cadernos de Educação Especial e Psico (PUC-RS). Na esfera internacional, tem contribuído para as revistas Interamerican Journal of Psychology, Revista Portuguesa de Educação, Revista Ideacción, Revista Psychologica, Gifted Education International e Gifted and Talented International, dentre outras.

A professora tem integrado comissões organizadoras e científicas de diversos congressos nacionais e internacionais de Psicologia. Já foi membro da diretoria da Associação Brasileira para Superdotados - DF (presidente), Associação Brasileira de Psicologia Escolar e Educacional (Conselho Fiscal), American Logos Foundation e Federação Ibero-Americana do Conselho Mundial para o Superdotado e Talentoso (Vice-Presidente). Foi, ainda, representante do Brasil no World Council for Gifted and Talented Children (1985-2000) e na Sociedade Interamericana de Psicologia (1990).

Desde 1995, a professora é pesquisadora nível IA do CNPq. Além disso, ela coordena, desde 2001, o grupo de pesquisa Processos Criativos e Superdotação, cadastrado no CNPq, que integra pesquisadores de distintas instituições de ensino superior (ver www.talentocriativo.com.br).

Como contribuição da professora Eunice Alencar à área de Psicologia no País, podemos ressaltar:

a) Pioneirismo nas áreas de criatividade e superdotação ao trazer tais temas para serem estudados no Brasil, após seu doutoramento no exterior.

b) Formação de pesquisadores nas áreas mencionadas, expandindo e multiplicando o número de estudiosos envolvidos com a área. Grande parte de seus ex-orientandos encontra-se, atualmente, em postos-chave em universidades, agências de fomento, ministérios, secretarias estaduais de educação etc, elaborando políticas educacionais, desenvolvendo projetos de pesquisa e/ou implementando programas de intervenção envolvendo as áreas de criatividade e superdotação.

c) Divulgação da produção científica brasileira no exterior, seja por meio de publicações de artigos e capítulos de livros ou apresentação em congressos internacionais. Vale destacar que a professora foi também pioneira, na década de 1970, na publicação de artigos em periódicos estrangeiros, prática incomum para a época.

d) Liderança na formação de grupos de pesquisa nas áreas de criatividade e superdotação, atuando como modelo de professora pesquisadora tanto para jovens cientistas quanto para os mais experientes, em termos de pioneirismo, domínio de conhecimento e postura ética.

\section{Contribuição a Políticas Públicas Educacionais e Tecnológicas}

Desde a década de 1980, a professora Eunice Alencar tem atuado como consultora de órgãos públicos, como Secretaria de Educação Especial do Ministério da Educação, CAPES, Secretaria de Educação do Distrito Federal, Fundação de Amparo à Pesquisa do Distrito Federal, do Rio Grande do Sul e de Pernambuco, Universidade de Brasília, Universidade Federal de Pernambuco, Universidade Federal de Santa Ca- 
tarina e SERPRO. Ela participou do comitê assessor da área de Psicologia do CNPq no período de 1989 a 1990, sendo a coordenadora no último ano.

No que tange à contribuição à política pública educacional e tecnológica brasileira, observa-se sua forte atuação na política governamental em termos de sua participação, como consultora, na elaboração de diretrizes curriculares e tecnológicas, bem como na recomendação e supervisão de práticas educacionais, técnicas e de pesquisa na implementação de projetos e programas de intervenções nos contextos educacionais e tecnológicos. Alicerçados em bases teóricas e evidências empíricas fornecidas pela professora Eunice Alencar, mudanças na condução de estudos, práticas e serviços na área de superdotação e criatividade têm sido realizadas, possibilitando, desta forma, atender as necessidades de crianças e adolescentes criativos e talentosos, como também orientar professores a lidarem com a diversidade em sala de aula.

Sua contribuição valiosa às políticas públicas educacionais e tecnológicas resultou na outorga de três distinções. Em 1998, foi agraciada com o Troféu Stella Prata, personalidade de destaque em Educação, oferecido pela Associação de Mulheres de Negócios e Profissionais do Distrito Federal. Além disso, em 2002 recebeu o título de Cidadã Honorária de Brasília pelo trabalho na área de Educação, outorgado pela Câmara Legislativa do Distrito Federal. Recentemente passou a integrar o Comitê Honorário Permanente do Conselho Brasileiro para Superdotação, em reconhecimento aos relevantes serviços prestados à área no País.

\section{Conclusão}

A outorga do título de professor emérito da Universidade de Brasília a Eunice Alencar é justa e merecida e representa o reconhecimento desta instituição por sua contribuição ao Instituto de Psicologia, à área de Psicologia, Educação e Tecnologia no País, tais como:

a) projeção do Instituto de Psicologia da UnB em nível nacional,

b) empenho na divulgação no exterior dos trabalhos realizados no Brasil,

c) iniciativa, dedicação e empenho nas atividades desenvolvidas durante o período como docente e pesquisadora da Universidade de Brasília,

d) envolvimento na formação de profissionais e pesquisadores, acolhendo e dando espaço para os jovens pesquisadores,

e) excelência de sua produção acadêmica,

f) compromisso com a qualidade do conhecimento produzido, seu pioneirismo e criatividade na implementação de novas áreas de pesquisa e programas acadêmicos em Psicologia,

g) lisura e postura ética inigualáveis na condução das tarefas acadêmicas e administrativas e

h) forte atuação no desenvolvimento de políticas públicas educacionais e tecnológicas.

Portanto, é chegado o momento de homenagear a professora Eunice Alencar que dedicou, com excelência e vigor, grande parte de sua vida a esta instituição e ao desenvolvimento da Psicologia no Brasil. 